\title{
Evaluating User Engagement with a Reminiscence App Using Cross Comparative Analysis of User Event Logs and Qualitative Data
}

Mc Cauley, C-O., Bond, RR., Ryan, A., Mulvenna, M., Laird, L., Gibson, A., Bunting, B., Ferry, F. R., \& Curran, K. (2019). Evaluating User Engagement with a Reminiscence App Using Cross Comparative Analysis of User Event Logs and Qualitative Data. Cyberpsychology, Behavior, and Social Networking, 22(8), 543-551. https://doi.org/10.1089/cyber.2019.0076

Link to publication record in Ulster University Research Portal

Published in:

Cyberpsychology, Behavior, and Social Networking

Publication Status:

Published (in print/issue): 12/08/2019

DOI:

10.1089/cyber.2019.0076

Document Version

Author Accepted version

\section{General rights}

Copyright for the publications made accessible via Ulster University's Research Portal is retained by the author(s) and / or other copyright owners and it is a condition of accessing these publications that users recognise and abide by the legal requirements associated with these rights.

\section{Take down policy}

The Research Portal is Ulster University's institutional repository that provides access to Ulster's research outputs. Every effort has been made to ensure that content in the Research Portal does not infringe any person's rights, or applicable UK laws. If you discover content in the Research Portal that you believe breaches copyright or violates any law, please contact pure-support@ulster.ac.uk. 


\section{Cyberpsychology, Behavior, and Social Networking}

Cyberpsychology, Behavior, and Social Networking: http://mc.manuscriptcentral.com/cyberpsych

\section{Evaluating User Engagement with a Reminiscence App Using Cross Comparative Analysis of User Event Logs and Qualitative Data}

\begin{tabular}{|r|l|}
\hline Journal: & Cyberpsychology, Behavior, and Social Networking \\
\hline Manuscript ID & CYBER-2019-0076.R1 \\
\hline Manuscript Type: & Original Article \\
\hline Keyword: & e-Health, Mobile technology, Qualitative Research, Quantitative Research \\
\hline $\begin{array}{r}\text { Manuscript Keywords (Search } \\
\text { Terms): }\end{array}$ & $\begin{array}{l}\text { Dementia, Reminiscence, Event logs, unsupervised machine learning, K- } \\
\text { means clustering, digital phenotype }\end{array}$ \\
\hline \multicolumn{2}{|r}{} \\
\end{tabular}

\section{SCHOLARONE \\ Manuscripts}


Title:

Evaluating User Engagement with a Reminiscence App Using Cross Comparative Analysis of User Event Logs and Qualitative Data

Running Head:

App evaluation using cross-comparative analysis

Introduction

Reminiscence refers to a range of interventions that prompt memories significant for an individual. Because reminiscence draws primarily on longer term memory, it is widely used as a therapeutic approach for people in the early stages of dementia. ${ }^{1,2,3}$ Reminiscence has become increasingly recognised as a psychosocial intervention which may be as effective as and even preferable to pharmacological interventions, especially to avoid unnecessary medication side-effects. ${ }^{4,5,6,7}$

The use of digital systems to facilitate reminiscing has been shown to be beneficial for people living with dementia. ${ }^{8}$ Technology that facilitates reminiscence increases opportunities for people living with dementia to participate in conversations and to enhance their social interactions. ${ }^{9,10}$ Many existing software systems, apps and social networking websites provide opportunities to gather and share multimedia resources. ${ }^{11}$ However, there is little research into the usability of these systems for reminiscing amongst people with deteriorating cognitive function. 
Lorenz et al. (2017) ${ }^{11}$ conducted a review to explore technology-based services for people living with dementia and their carers and identified the role of technology in supporting therapeutic interventions and home-based reminiscence to reduce caregiver burden. ${ }^{12}$ While Lorenz et al. (2017) ${ }^{11}$ acknowledged the significant role technology can play in supporting connection, communication and independent living, they also highlighted the challenges posed by the ever-changing cognitive status of users. This was supported by other studies recommending that technologies for people living with dementia and their caregivers need to be accessible at the right time, adaptable to changing needs, easy to use and inexpensive to buy. ${ }^{13,14}$ Advances in digital technology have enabled opportunities for supportive interventions, such as reminiscence to be conducted in the home. ${ }^{14}$ However, technologyfacilitated reminiscence has its challenges, since it relies on the caregiver's willingness to participate and source memorabilia. ${ }^{15}$

Many authors have described the learning potential of people living with dementia, ${ }^{16,17,18}$ whereas, Riley et al. (2009) ${ }^{19}$ refer to the inability of people living with dementia to learn new skills. It is noteworthy that in their review on involving people living with dementia in the development of digital applications, Span et al. (2013) ${ }^{20}$ concluded that cognitive impairment is no reason to exclude people living with dementia from research. Recent research into technology-facilitated reminiscence has shown that it can facilitate opportunities for people living with dementia to retain an empowered role in conversations and relationships. ${ }^{1}$ However, as there is a lack of research that evaluates the actual usage and adoption of these technologies amongst people living with dementia and carers, this study contributes to a deeper understanding of this process. 
This research was part of a wider feasibility study designed to investigate the outcomes of a home-based individual specific reminiscence intervention through the use of a co-created iPad app known as InspireD for people living with dementia and their family carers, implemented with a paired sample of 30 people living with mild to moderate dementia and their family carers. That study is detailed in previously reported work by the authors ${ }^{20}$. The intervention consisted of reminiscence training, information technology based (IT) training and a 12-week period of independent use of the InspireD app to support individual specific reminiscence in the home.

The aim of the study reported here was to evaluate the user experience of a reminiscence app by people living with dementia and their family carers by cross-comparing the event log data that is automatically generated from the app usage, with the qualitative lived experience of using the technology.

The objectives were to use machine learning to identify behavioral clusters which typify the different user engagements with the InspireD app; to cross-compare the event log data generated by app usage with quantitative data on previous participant experience; and to contextualize behavioral cluster patterns with the process themes generated from the qualitative interview analysis. The rationale for using machine learning to identify and typify user engagements was to assess if such unsupervised machine learning techniques could uncover realistic patterns that would be of use to the study.

Method 
This study was conducted in a large health and social care trust in the UK, with recruitment facilitated by Trust staff and the UK Alzheimer's Society. Event log data were collected from all participating dyads $(n=30)$ throughout the 12 -week period of InspireD app home usage; however, data files for two dyads were corrupted and not used. Individual interviews were conducted with a volunteer sample of participants at the end of the study (interviews: 16 people living with dementia and 16 family carers). Ethical approval for this study was granted from Ulster University's Research Ethics Committee, the regional ORECNI and the NHS Trust's Research and Development office.

\section{Data Collection}

Event logging is when each user interaction with an app is automatically logged and stored in a database. This study adopted the health interaction log data analysis (HILDA) pipeline, ${ }^{22}$ which involved data cleaning and preparation as well as the use of exploratory data analysis and K-means clustering to uncover behavioural patterns of usage by users of the InspireD reminiscence app.

\footnotetext{
A qualitative approach is an appropriate methodological choice when an understanding of how an individual experienced a phenomenon is necessary. ${ }^{23}$ In the context of this study, semi-structured interviews with participants facilitated the presentation of key trends whereby qualitative findings were compared to the 'ground truth' of the multiple strands of electronic data conducted within the wider study. ${ }^{24}$
} 
Event logging involves storing three variables, namely: 1) the unique user ID to denote who made the interaction, 2) the date and time stamp to denote when the interaction occurred and 3) the event name that describes the interaction. Individual interviews facilitated a more indepth exploration of participants' perspectives about key aspects of the study. The researcher used an interview schedule, which included questions on the reminiscence training, IT support, use of the app and reminiscence activity. The interviews lasted no longer than 45 minutes.

Quantitative data analysis

$\mathrm{R}$ studio and the R programming language were used for statistical programming. Hypothesis testing included t-tests, Wilcoxon and Chi-square tests where appropriate $(\mathrm{p}<0.05$ was considered statistically significant). Different users started the 12 -week trial at different times, therefore data preparation involved transforming the dates of each interaction/event into common trial days (from 1 to 84 ) to allow for comparable usage patterns between all users over the 84 days. This also facilitated exploratory data analysis and the visualisation of each user journey using dot plots.

K-means clustering is an unsupervised machine learning technique that was used to uncover the number of archetypal users that existed. Given a series of variables that describe a user, K-means clustering computes clusters of users who have similar characteristics. In this study, we chose five variables to characterise each user. This included: 1) the number of interactions the person living with dementia had with the app, 2) the number of interactions the carer had with the app, 3) the number of unique day interactions the person living with dementia had 
with the app, 4) the mean day interval between each unique day interaction, and 5) the standard deviation of the intervals between each unique day interaction. When combined these variables are sufficient to characterise, 1) the relationship between the person living with dementia and the carer's interactions with the app, and 2) the frequency of these interactions and the consistency or variability of this frequency. After determining clusters, principal component analysis was used to visualise the clusters on a 2-dimensional plot (clues plot).

Interview questions pertaining to participants' usage patterns provided the team with an invaluable presentation of comparable data from the 'ground truth' of the event logging data with participants' previous experience in relation to the intervention. The use of Miles and Huberman's (2014) ${ }^{25}$ checklist matrix (see Table 1) was employed as it not only enabled the exploration of all participants' responses to one key variable, but it enabled the display of an individual participants' responses to a range of variables.

Qualitative Thematic Analysis

The qualitative stage of analysis was conducted using Braun and Clarke's (2006) ${ }^{26}$ sixphased method of analysis, as this provided the flexibility and responsiveness necessary for a rich and dynamic approach to analysis. Braun and Clarke (2006, p.87) ${ }^{26}$ six-phased method of analysis is comprised of the following steps: familiarizing yourself with your data; generating initial codes; searching for themes; reviewing themes; defining and naming themes; and producing the report. 
Lincoln and Guba's (1985) ${ }^{27}$ four criteria of credibility, dependability, transferability and confirmability was used to maximise the credibility of the qualitative data with research team members discussing and agreeing the final themes and sub-themes.

Results

Figure 1 shows basic exploratory data analysis of event logs. A total of $71 \%$ of the interactions from people living with dementia are within the reminiscing screens in the app, which is more than carer interactions $(\mathrm{p}<0.001)$. Figure 1 (A) shows that people living with dementia preferred to interact with photos and reminisce with personalised media. Reminiscing peaked on Thursdays and Fridays but dipped at the weekends. There are peaks of reminiscing at $11 \mathrm{am}, 3 \mathrm{pm}$ and $8 \mathrm{pm}$.

[Figure 1 about here]

There is a correlation between the number of days the people living with dementia and carer interacted with the app $(\mathrm{r}=0.577, \mathrm{p}<0.001)$. However, people living with dementia had many more interactions than carers. People living with dementia interacted with the app on $13.73 \%$ of the days, which is akin to one reminiscence session per week. The median interval between each exclusive day using the app was 7.10 days; hence, if a person living with dementia used the app on a given day they are not likely to use this again until one week 
later. Figure $2(\mathrm{a} \& \mathrm{~b})$ shows the interaction events over a time-line (where the $\mathrm{x}$-axis denotes days). A horizontal jitter was applied to each dot to show the density of interactions per day.

[Figure 2a about here]

[Figure $2 \mathrm{~b}$ about here]

Figure $2(\mathrm{a} \& \mathrm{~b})$ shows that each dyad has a unique experience eliciting various usage patterns, where some indicate short bursts of activity. Table 1 illustrates the participants' previous IT and reminiscence training and usage patterns generated from qualitative interviews.

[Table 1 about here]

K-means clustering uncovered four clusters or user archetypes. The description of the centroid characteristics of each cluster is provided in Table 2.

[Table 2 about here] 
Figure 3 shows a two-dimensional visualisation of the four clusters but does not fully represent the uniqueness of the clusters, given the inability to visualise data points in highdimensional space.

[Figure 3 about here]

Figure 4 provides box-plots that show how each individual feature compares across each cluster. Whilst this shows the extent to which each individual feature discriminates between the clusters, one must bear in mind that it is the combination of all features that provide the discrimination in K-means.

[Figure 4 about here]

Interview Findings

The four themes that emerged through analysis were: Cluster 1- "I'm starting to get really good"; Cluster 2- "Able to keep me right"; Cluster 3- "It was a very difficult mountain to climb"; and Cluster 4- "If I wanted to use it...she was here". These are described in sequence below.

Cluster 1: "I'm starting to get really good" 
One person living with dementia repeatedly engaged with the system $(3.6 \%$ or 1 user per 28 users), as they had 7.2 times more interactions than their carer. Whilst the person living with dementia enthusiastically used the app, the carer showed a normal amount of usage, hence the person living with dementia was independently dedicated. The independent people living with dementia and carer used the app for over half the days in a month (55\% of days) and, with little variability, used the app every two days.

\begin{abstract}
"I forgot quite a bit but X (carer) has a good memory and she was able to keep me right. Just the basic things now. I'm starting to get really good. I'm faster as well. “(Hugh')
\end{abstract}

Cluster 2: "Able to keep me right"

The majority of people living with dementia (43\%) fall into this cluster, hence making them the most typical usage profile. These people living with dementia has only 1.7 times more interactions with the app than their carer. This indicates that these people living with dementia have some dependence on the carer for app usage. This dyad uses the app $15 \%$ of days in a month. This dyad used the app unpredictably, but on average interacts with it every 6.61 days (approximately once per week).

"Aye, it was grand. I would be very, very slow in picking a thing up, but I'm getting on to it
now. The wife knows a bit about it so she can help me." (Peter)

${ }^{1}$ All names changed to protect identities 
For the carers, the process of reminiscence training also offered them the time to share memories which were defining to their relationship and history.

\author{
"Oh, it's lovely to have them and nice to look back...I would have photographs and every \\ year or so you might look through them, but apart from that, no, you never would have \\ bothered." (Sally)
}

It was evident that in the dyads who struggled to use the app or admitted infrequent usage, the carer acknowledged they had not adapted well to this type of technology or had felt this type of medium was not appropriate for their loved one.

\author{
"I would put the whole thing down to me. I'm not accepting of it. I wasn't maybe doing as \\ much as I should have been doing. " (Ann)
}

Cluster 3: "It was a very difficult mountain to climb"

This reflects $25 \%$ of people living with dementia as they had $25 \%$ fewer interactions with the app than the carer. These dyads use the app $9 \%$ of the days in a month and can typically go for 20 days without using it, making them the least consistent users. However, whilst the people living with dementia had fewer interactions than their carer, they did enjoy using the app. 


\author{
“Well, there's nothing to actually stop me from using it. That's number one. And I like using \\ it." (Denis)
}

The carer had fewer interactions than other carers in all other clusters and felt that, regardless of the training received, they found they had a limited interest engaging with it.

\begin{abstract}
"Well definitely for some people who are not au fait with computers ...it was a very difficult mountain to climb...I am neither a TV fan or a radio fan or any...I have no interest in any of them things at all...not at all." (Nuala)
\end{abstract}

By using the photographs or memorabilia the dyad already owned, the process enabled the shared memories they captured to become the focal point of the reminiscence training.

\begin{abstract}
“it brought me back a good bit, like, you understand life, you know. I was a go, go guy... I wouldn't have had time for anything like that in my life, but when I seen this, this, sort of, made me sit up and take notice”. (Denis)
\end{abstract}

Cluster 4: "If I wanted to use it...she was here"

This reflects $29 \%$ of people living with dementia - the second largest usage categorisation. These people living with dementia had $36 \%$ fewer interactions with the app than their carers. 
The carers are very enthusiastic and have more interactions than other carers in all other clusters. Similar to the typical users in cluster 2 , these dyads interact with the app $16 \%$ of the days in a month and on average use the app every 6.97 days.

\begin{abstract}
"He would never, he was always kind of afraid to switch it on himself... He would always say, 'no I'll wait on X, oh no I can't'... He was afraid, he had this apprehension of ... maybe, oh I'd mess things ... He thinks he's going to lose the photographs."(Helen)
\end{abstract}

Discussion

The aim of this paper was to evaluate dyad engagement of the InspireD app through a novel cross-comparative analysis of clusters identified from machine learning using k-means clustering, dervived from the event logging data generated from app usage, together with the qualitative experience of the process. Event log data for 28 dyads were presented, outlining the behavioural usage of each participant. From this, four clusters of behavioural usage were identified based on five usage characteristics. This data was analysed with interview data for 16 dyads.

In previous research studies, authors have identified the potential for people with dementia to learn new skills and thereby maintain their quality of life at home. Three of the four clusters derived from the machine learning of the event log data are in concordance with this literature. These three clusters demonstrate that it is the case that people with dementia together with their carers report a sense of gain and self-confidence. 
Four themes pertaining to the four clusters of different behavioural usage patterns were identified. The first thematic categorisation was Cluster 1: 'I'm starting to get really good', which described the enthusiastic usage of one dyad, particularly the usage patterns of the person living with dementia. Electronic data revealed that the person living with dementia was using the InspireD app 7.2 times more than their carers which would indicate independent and self-reliant usage.

The second thematic categorisation was Cluster 2: "Able to keep me right", which described the majority of usage patterns for people living with dementia. Event logging data revealed that the people living with dementia engaged with the InspireD app 1.7 times more than their carer, thus showing a level of dependence in their usage. Twelve of the interviewed carers indicated they had some basic previous IT experience. It could therefore be argued that previous carer IT experience was a determinant of InspireD usage. Despite this, all participants found the IT training to be helpful and a significant support within their own usage. This is evident in Figure 2, where electronic usage among Cluster 2 dyads is greatest following the last IT training session and then begins to reduce throughout the duration of home use.

The research team observed that some dyads who were less enthusiastic about the intervention occasionally referred to their difficulty in adapting to a caregiving role. This was confirmed by the event logging data, which thematically categorised three dyads in Cluster 3also reflected in the theme: 'It was a very difficult mountain to climb'. It is interesting to note none of the Cluster 3 dyads had any previous reminiscence experience, and only two carers 
had previous IT experience. However, further analysis revealed Cluster 3 people living with dementia found the process of reminiscence training "made me sit up and take notice". This would indicate that for Cluster 3 people living with dementia engagement was not maintained throughout the intervention.

The event log data indicated some carer disengagement; however, this is not fully captured in the qualitative data. Of the 16 carers interviewed, only three revealed they felt they played a role in poor technology adoption, as 'I am not accepting of it' (Ann, Cluster 2). When comparing the qualitative and electronic data, only one carer was categorised in Cluster 3 while the other two carers (Cluster 2) and (Cluster 4) did, in fact, demonstrate considerable support. This could suggest that the carers were either unduly self-critical or did not view their lack of engagement to be a contributing factor for poor usage. This finding resonates with O'Connor et al.'s (2016) ${ }^{28}$ proposition, that negatively held carer views on technology was not only a significant limitation on the development of technological programmes for people living with dementia but reduced the potential to enhance their relationship through a shared activity.

The cross-comparative analysis suggested that those living with dementia felt nervous of the technology and relied on their carer who was 'able to keep me right' in Cluster 2 and 'If I wanted to use it she was there' in Cluster 4, providing various levels of IT support throughout the duration of home use. As previously proposed ${ }^{15}$, with appropriate carer support those living with dementia were able to develop a level of independent use as demonstrated in Cluster 1 (1 dyad) and Cluster 2 (6 dyads). The 6 dyads in Cluster 4 did require more carer 
engagement than the other clusters, but this could be indicative of where they are in their own dementia journey.

The main limitation of this work in comparing qualitative interview data with thematic clusters derived from the event log usage of a reminiscing app is that the machine learning algorithms operate on quite a small data set, derived from the small dyad size of the primary study. Another limitation is the loss of data from one dyad, which represents the problems of utilising real world data for research purposes.

\section{Conclusions}

The novel cross-comparative analysis of clusters derived from machine learning of event log data, and qualitative interview data provides significant insights of actual app usage contextualised by the key elements which facilitated involvement in the intervention and supported engagement for those living with dementia. Carer engagement in the process was vital to support participants living with dementia. However, the cross-comparison of data revealed that the nature of the relationship was a significant factor for dyads less engaged with app usage (Cluster 3).

The paper clearly shows the value in future work of combining objective clusters derived from machine learning of event log data, and qualitative data to understand user engagement. Both methods are complementary. This work indicates the value of adding qualitative data to enrich the description of clusters elicited by unsupervised machine learning. User event log analysis can inform us of 'what patterns exist', and qualitative interview data can inform us of 
'why certain patterns exist'. Together, augmenting qualitative data with usage data provides key insights into the benefits of using mixed-methods for evaluating human-computer interaction technologies and offers new insights for future research in this area.

Digital phenotyping is an emerging term given to the capturing and use of user log data from health and wellbeing technologies used in apps. ${ }^{29,30,31}$ Significant ethical questions arise as machine learning of digital phenotype usage data become more commonplace. In particular, for vulnerable app users such as people with dementia, to what degree can self-management of their care be supported by, for example, personalized care provided by machine learning of digital phenotype usage data? 
Figure legends

Figure 1. A) shows the number of interactions with different types of media for reminiscing, B) shows the number of interactions per personal and general media, C) shows the number of interactions per hour of the day and D) shows the number of interactions per day.

Figure 2. a) - Usage patterns of Dyad's interacting with the InspireD app -Dyads 1-16 (G= reminiscing using generic media, $\mathrm{P}=$ reminiscing using personal media, $\mathrm{Admin}=\mathrm{Carer}$ interactions)

Figure 2. b) - Usage patterns of Dyad's interacting with the InspireD app -Dyads $17-30(\mathrm{G}=$ reminiscing using generic media, $\mathrm{P}=$ reminiscing using personal media, Admin $=$ Carer interactions)

Figure 3. Behavioural usage clusters depicted in two-dimensions using principal component analysis.

Figure 4. Each box-plot shows the distribution of each variable in each cluster. This shows the extent to which each individual feature discriminates between the clusters. 


\section{References}

1. Gibson F. Reminiscence and life story work: A practice guide. London: Jessica Kingsley Press 2011. ISBN: 9781849051514.

2. Woods RT, Orrell M, Bruce E, Edwards, RT, Hoare Z, Hounsome B, Keady J, Moniz-Cook ED, Orrgeta V, Orrell M, Rees J, Russell IT. REMCARE: pragmatic multi-centre randomised trial of reminiscence groups for people with dementia and their family carers: effectiveness and economic analysis. PLoS One 2016;11(4):e0152843. PMID:27093052

3. Subramaniam P, Woods B. The impact of individual reminiscence therapy for people with dementia: systematic review. Expert Rev Neurother 2012;12(5):545-55. PMID:22550983

4. Robinson L, Hutchings D, Dickinson HO, Corner L, Beyer F, Finch T, Hughes J, Vanoli A, Ballard C, Bond J. (2007) Effectiveness and acceptability of non-pharmacological interventions to reduce wandering in dementia: a systematic review. Int $J$ Geriatr Psychiatry. 22(1): 9-22.

5. Fossy, J., James, I. 2008. Evidence-based approaches for improving dementia care in care homes. London, Alzheimer's Society.

6. Lawrence. V., Fossey. J., Ballard. C., Moniz-Cook. E., and Murry. J (2012) Improving quality of life for people with dementia in care homes: Making psychosocial interventions work. The British Journal of Psycharity. 201 pp 344-351.

7. Brooker, D.J., Latham, I., Evans, S.C., Jacobson, N., Perry, W., Bray, J., Ballard, C., Fossey, J., Pickett, J. 2016. FITS into practice: translating research into practice in reducing the use of anti-psychotic medication for people with dementia living in care homes. Aging \& Mental Health, 20 (7), doi.org/10.1080/13607863.2015.1063102.

8. Lazar A, Thompson H, Demiris G. A systematic review of the use of technology for reminiscence therapy. Health Education and Behaviour, 41 (15) (2014): 515-615.

9. Subramaniam P \& Woods B. Digital life storybooks for people with dementia living in care homes. Clinical Interventions in Aging, 11, (2016): 1263-1276.

10. Ryan, A.A., McCauley, C.O., Laird, E.A., Gibson, A., Mulvenna, M.D., Bond, R., Bunting, B., Curran, K and Ferry, F. 2018. "There is still so much inside": The impact of homebased, personalised reminiscence, facilitated through an iPad app, on people living with dementia and their family carers. Dementia doi.org/10.1177/1471301218795242

11. Lorenz K, Freddolino P, Comas-Herrera A, Knapp M, Damant J. Technology- based tools and services for people with dementia and carers: Mapping technology onto the dementia care pathway. Dementia 8(2) (2017) : 725-741

12. O'Shea E, Devane D, Cooney A, Casey D, Jordan F, Hunter A, Murphy E, Newell J, Connolly S \& Murphy K The impact of reminiscence on quality of life of residents with Dementia in long stay care. International Journal of Geriatric Psychiatry, 29, (2014): 1062-1070.

13. Mulvenna MD, Doyle L, Wright T, Zheng H, Topping P, Boyle K. \& Martin S Evaluation of card-based versus device-based reminiscing using photographic images. Journal of CyberTherapy and Rehabilitation, 4(1), (2011): 57-66.

14. Karlsson E, Axelsson K, Zingmark K, Fahlander K, Savenstedt S “Carpe Diem” Supporting conversations between individuals with dementia and their family members. Journal of Gerontological Nursing, 40 (2), (2014): 38-46.

15. Sarne-Fleischmann V \& Tractinsky N Development and evaluation of a personalised multimedia system for reminiscence therapy in Alzheimer's patients. International Journal of Social and Humanistic Computing, 1(1), (2008): 8195.

16. Dechamps A, Fasotti L, Jungheim J, Leone E, Dood E, Allioux A Effects of different learning methods for instrumental activities of daily living in patients with Alzheimer's 
dementia: A pilot study. Journal of Alzheimer's Disease and other Dementias. 26, (2011): 273-281

17. Hanson E, Magnusson L, Arvidsson H, Claesson A, Keady J, Nolan M Working together with persons with early stage dementia and their family members to design a user-friendly technology-based support service. Dementia, 6 (3), (2007): 411-434

18. van Tilborg IA, Kessels RPC, Hulstijn W How should we teach everyday skills in dementia? A controlled study comparing and explicit training methods. Clinical Rehabilitation 25, (2011): 638-648

19. Riley P, Alm N, Newell A An interactive tool to promote musical creativity in people with dementia. Computers in Human Behaviour, 25, (2009): 599-608.

20. Laird, LEA, Ryan, A, Mc Cauley, C, Bond, RR, Mulvenna, M, Curran, K, Bunting, B, Ferry, FR \& Gibson, A 2018, 'Using mobile technology to provide personalised reminiscence for people living with dementia and their carers: An appraisal of outcomes from a quasi-experimental study', JMIR Mental Health, vol. 5, no. 3, e57. https://doi.org/10.2196/mental.9684.

21. Span M, Hettinga M, Vernooij-Dassen M, Eefstinge J, Smits C Involving people with dementia in the development of supportive IT applications: A systematic review. Ageing Research Reviews, 12, (2013): 535-551. doi.org/10.1016/j.arr.2013.01.002

22. Mulvenna, M.D., Bond, R., Grigorash, A., O'Neill, S., and Ryan, A., HILDA - A Health Interaction Log Data Analysis Workflow to Aid Understanding of Usage Patterns and Behaviours, In: The 2nd Symposium on Social Interactions in Complex Intelligent Systems (SICIS) at Artificial Intelligence and Simulation of Behaviour Convention (AISB-2018), Liverpool. Society for the Study of Artificial Intelligence and Simulation of Behaviour, 2018.

23. Creswell, J.W. 2013. Qualitative Inquiry and Research Design: Choosing Among Five Approaches. $3^{\text {rd }}$ ed. London: Sage.

24. Denzin, N.K and Lincoln, Y.S. 2013. Strategies of Introduction. In: Denzin, N.K and Lincoln, Y.S., ed. Strategies of Qualitative Inquiry. California: Sage. 1-35.

25. Miles, M.B., Huberman, A.M. 1994. Qualitative Data Analysis: An Expanded Sourcebook. $2^{\text {nd }}$ ed. California: Sage Publications.

26. Braun V. Clarke V Using thematic analysis in psychology. Qualitative Research In Psychology, 3, (2006):77-101

27. Lincoln, Y.S., Guba, E.G. 1985. Naturalistic Inquiry. Beverly Hills, CA: Sage Publications

28. O'Connor S, Bouamrane MM, O'Donnell CA \& Mair FS Barriers to co-designing mobile technology with persons with dementia and their carers. Nursing Informatics, 2016, doi: 10.3233/978-1-61499-658-3-1028.

29. Martinez-Martin, Nicole, Thomas R Insel, Paul Dagum, Henry T Greely, and Mildred K Cho. 2018. "Data Mining for Health: Staking out the Ethical Territory of Digital Phenotyping." Npj Digital Medicine 1 (1): 68. doi:10.1038/s41746-018-0075-8.

30. Insel, Thomas R. 2018. "Digital Phenotyping: A Global Tool for Psychiatry." World Psychiatry: Official Journal of the World Psychiatric Association (WPA) 17 (3). John Wiley \& Sons, Inc.: 276-77. doi:10.1002/wps.20550.

31. Torous, John, Patrick Staples, Ian Barnett, Luis R Sandoval, Matcheri Keshavan, and Jukka-Pekka Onnela. 2018. "Characterizing the Clinical Relevance of Digital Phenotyping Data Quality with Applications to a Cohort with Schizophrenia.” Npj Digital Medicine 1 (1): 15. doi:10.1038/s41746-018-0022-8. 


\begin{tabular}{|c|c|c|c|c|c|}
\hline $\begin{array}{l}\text { Total } \\
\text { Number of } \\
\text { Dyads }\end{array}$ & $\begin{array}{l}\text { Completed } \\
\text { reminiscence } \\
\text { activity before? }\end{array}$ & $\begin{array}{ll}\text { Previous } & \text { IT } \\
\text { experience? } & \end{array}$ & $\begin{array}{l}\text { Preferred } \\
\text { functionality }\end{array}$ & $\begin{array}{l}\text { Event logging } \\
\text { data }\end{array}$ & $\begin{array}{l}\text { Function } \\
\text { most } \\
\text { commonly } \\
\text { used }\end{array}$ \\
\hline $\begin{array}{l}\text { Total } \\
16 \text { Dyads } \\
(n=30)\end{array}$ & $\begin{array}{l}14 \text { PLWD-No } \\
0 \text { PLWD-Yes } \\
13 \text { Carers-No } \\
3 \text { Carers- Yes }\end{array}$ & $\begin{array}{l}12 \text { PLWD-No } \\
2 \text { PLWD- Yes } \\
4 \text { Carers-No } \\
\text { 12Carers- Yes }\end{array}$ & $\begin{array}{l}3 \text { Dyads enjoyed } \\
\text { music/photos } \\
\text { 14Dyads } \\
\text { enjoyed photos/ } \\
\text { music }\end{array}$ & $\begin{array}{l}1 \text { Dyad enjoyed } \\
\text { music/photos } \\
15 \quad \text { enjoyed } \\
\text { photos/music }\end{array}$ & $\begin{array}{l}2 \quad \text { Dyads } \\
\text { am/early } \\
\text { afternoon }\end{array}$ \\
\hline
\end{tabular}

Table 1. Participant training and usage profiles (PLWD = People living with dementia) 


\begin{tabular}{|c|c|c|c|c|c|c|c|}
\hline Cluster & Description & $\begin{array}{l}\text { Cluster } \\
\text { size } \\
\text { (\#dyads) }\end{array}$ & $\begin{array}{l}\text { Number of } \\
\text { PLWD } \\
\text { interactions }\end{array}$ & $\begin{array}{l}\text { Number of } \\
\text { carer } \\
\text { interactions }\end{array}$ & $\begin{array}{l}\text { Number of } \\
\text { PLWD } \\
\text { unique day } \\
\text { interactions }\end{array}$ & $\begin{array}{l}\text { Mean day } \\
\text { interval } \\
\text { between } \\
\text { interactions }\end{array}$ & $\begin{array}{l}\text { Standard } \\
\text { deviation of } \\
\text { interval } \\
\text { between } \\
\text { interactions }\end{array}$ \\
\hline 1 & $\begin{array}{l}\text { A PLWD } \\
\text { who } \\
\text { demonstrates } \\
\text { independent } \\
\text { and } \\
\text { consistent } \\
\text { use of the app }\end{array}$ & $1(4 \%)$ & 572.00 & 79.00 & 46.00 & 2.00 & 2.28 \\
\hline 2 & $\begin{array}{l}\text { A PLWD } \\
\text { who is reliant } \\
\text { on his/her } \\
\text { carers for } \\
\text { support with } \\
\text { the app and } \\
\text { exhibits } \\
\text { unpredictable } \\
\text { usage } \\
\text { patterns }\end{array}$ & $\begin{array}{l}12 \\
(43 \%)\end{array}$ & 134.83 & 78.42 & 12.58 & 6.61 & 8.05 \\
\hline 3 & $\begin{array}{l}\text { A PLWD } \\
\text { who is highly } \\
\text { reliant on } \\
\text { his/her carers } \\
\text { for } \\
\text { engagement } \\
\text { with the app. } \\
\text { This user has } \\
\text { little } \\
\text { interaction } \\
\text { with } \\
\text { extremely } \\
\text { unpredictable } \\
\text { and } \\
\text { inconsistent } \\
\text { usage } \\
\text { patterns }\end{array}$ & $7(25 \%)$ & 38.28 & 51.14 & 5.71 & 19.66 & 14.71 \\
\hline 4 & $\begin{array}{l}\text { Infrequent } \\
\text { user }\end{array}$ & $8(29 \%)$ & 127.00 & 200.25 & 13.50 & 6.97 & 8.99 \\
\hline
\end{tabular}

Table 2. A description of the four clusters using statistics from the centroids of each cluster, hence describing an average dyad in that cluster (PLWD = People living with dementia) 

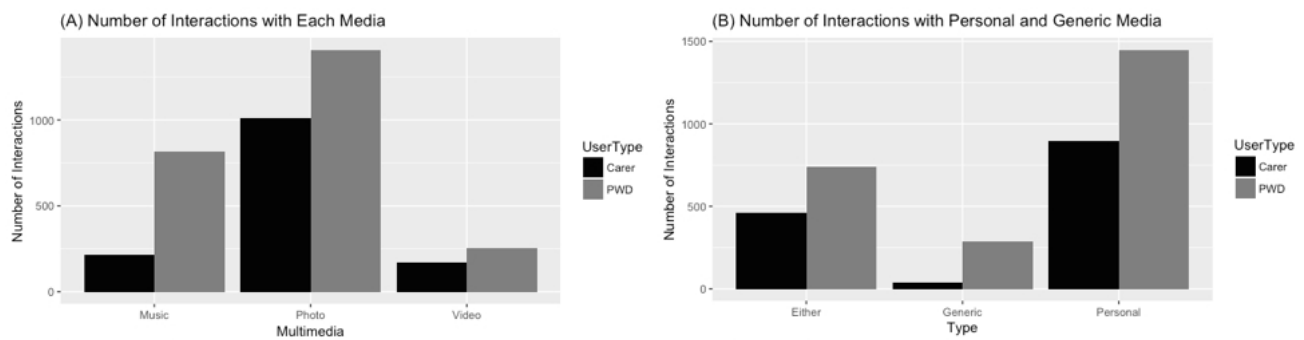

(C) Number of Interactions Per Hour (D) Number of Interactions Per Day
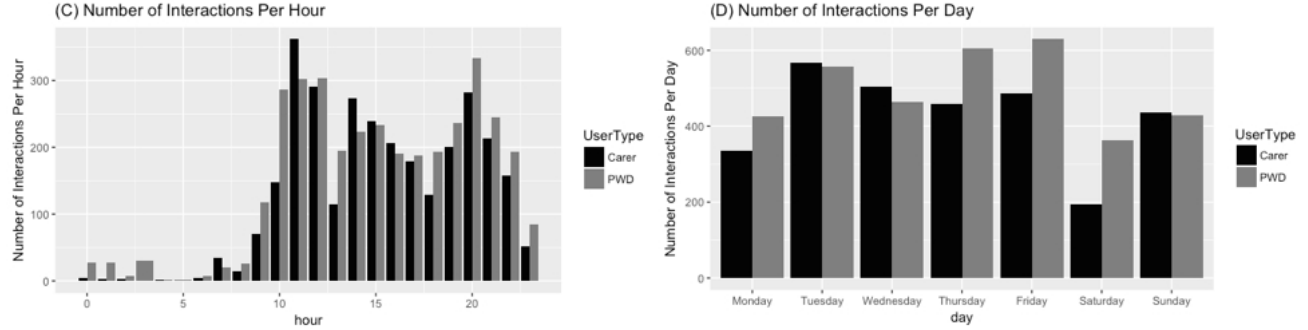

Figure 1. A) shows the number of interactions with different types of media for reminiscing, B) shows the number of interactions per personal and general media, C) shows the number of interactions per hour of the day and D) shows the number of interactions per day.

$164 \times 84 \mathrm{~mm}(150 \times 150 \mathrm{DPI})$ 

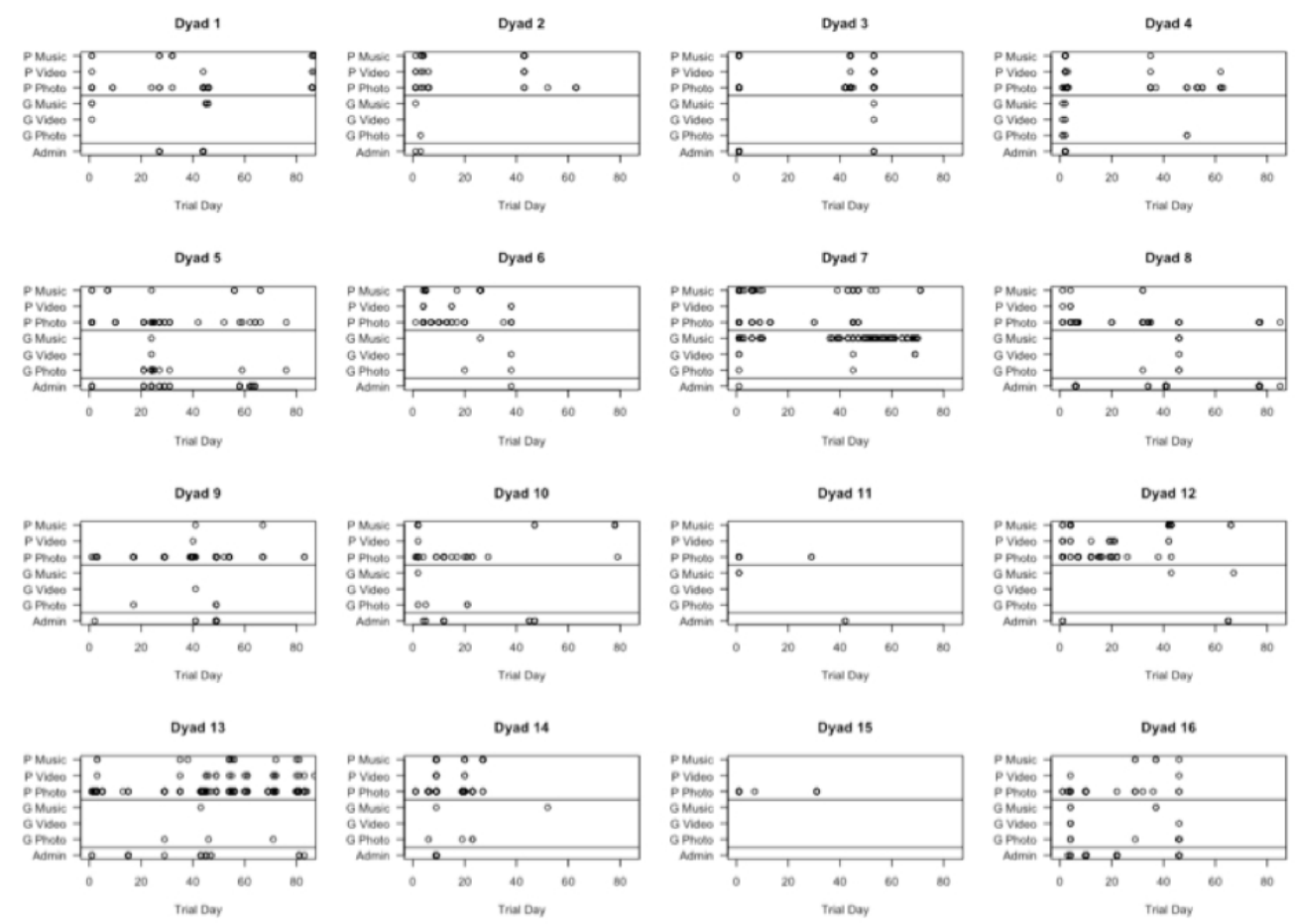

Figure 2. a) - Usage patterns of Dyad's interacting with the InspireD app -Dyads 1-16 ( $G=$ reminiscing using generic media, $\mathrm{P}=$ reminiscing using personal media, $\mathrm{Admin}=$ Carer interactions)

$159 \times 115 \mathrm{~mm}(150 \times 150 \mathrm{DPI})$ 

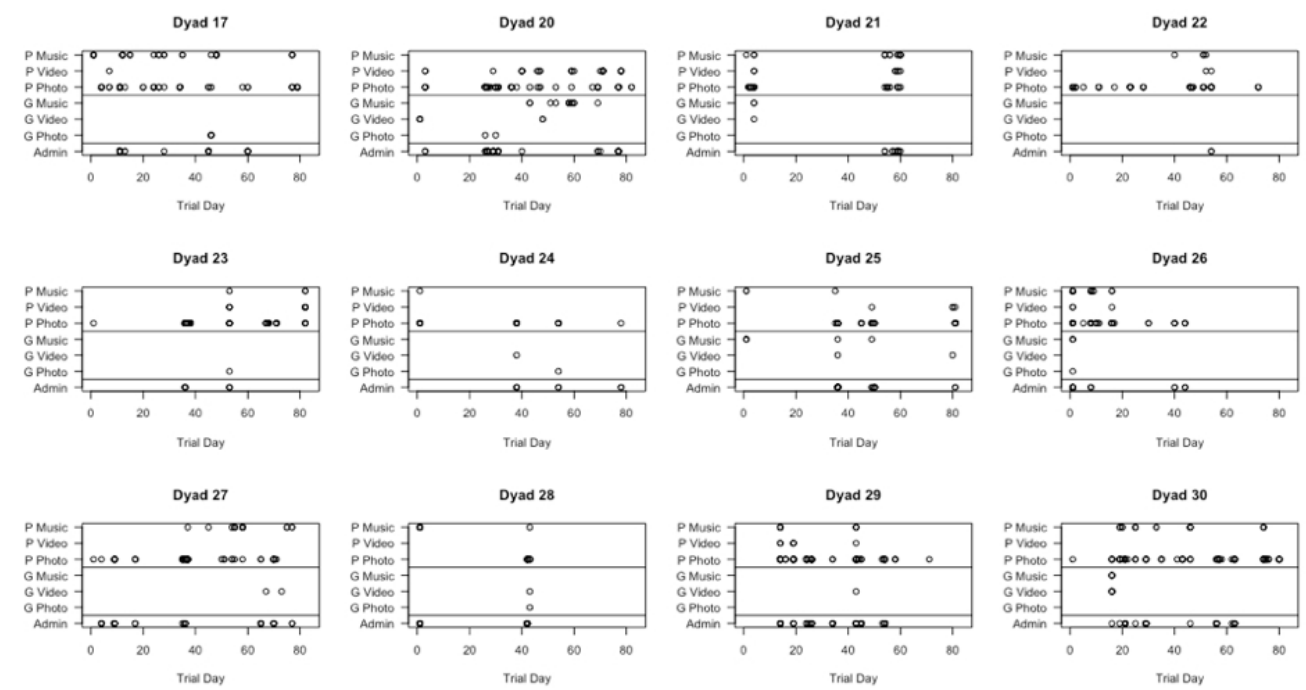

Figure 2. b) - Usage patterns of Dyad's interacting with the InspireD app -Dyads 17-30 (G= reminiscing using generic media, $\mathrm{P}=$ reminiscing using personal media, $\mathrm{Admin}=$ Carer interactions)

$159 \times 85 \mathrm{~mm}(150 \times 150 \mathrm{DPI})$ 


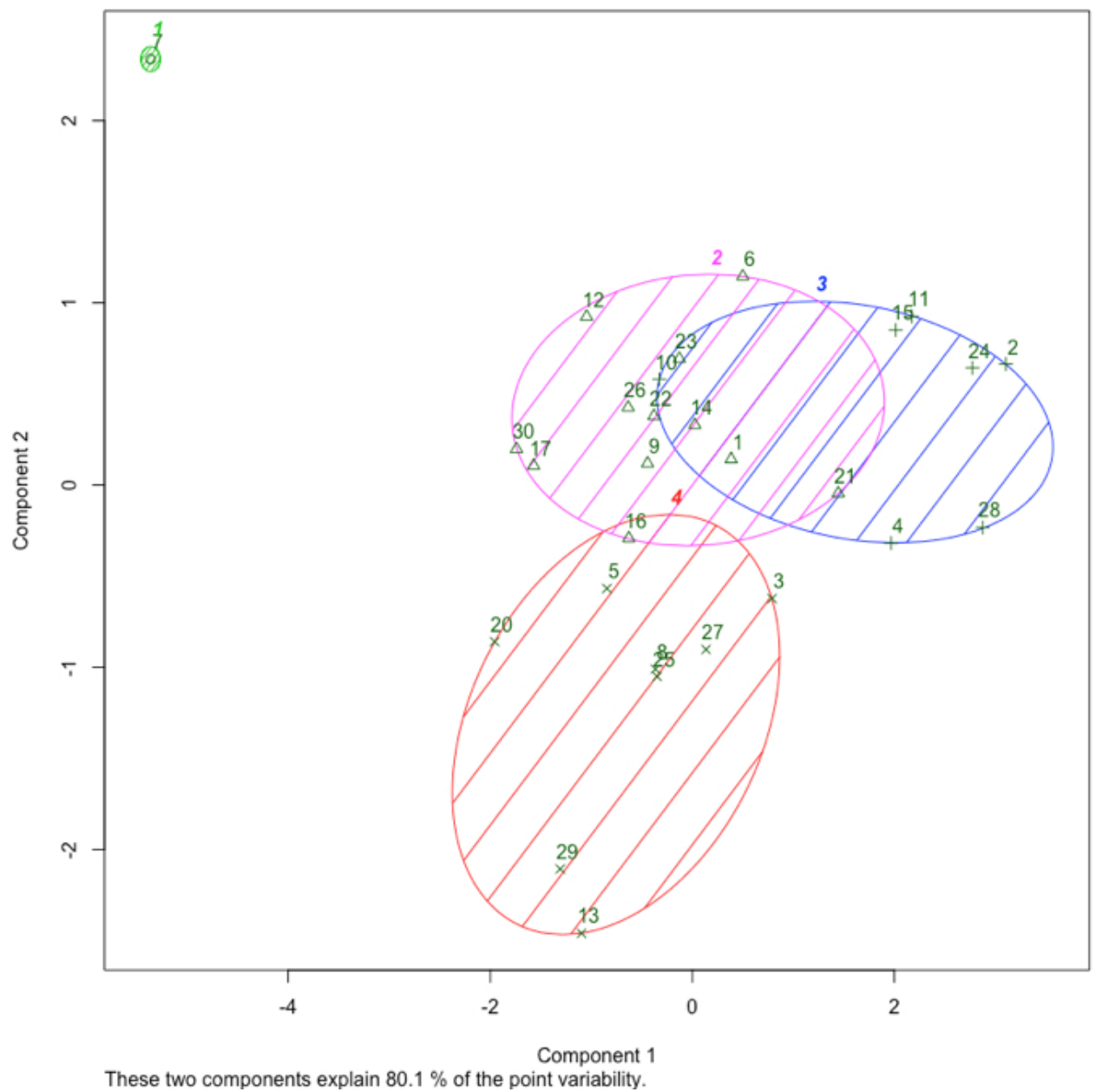

Figure 3. Behavioural usage clusters depicted in two-dimensions using principal component analysis.

$118 \times 114 \mathrm{~mm}(150 \times 150 \mathrm{DPI})$ 

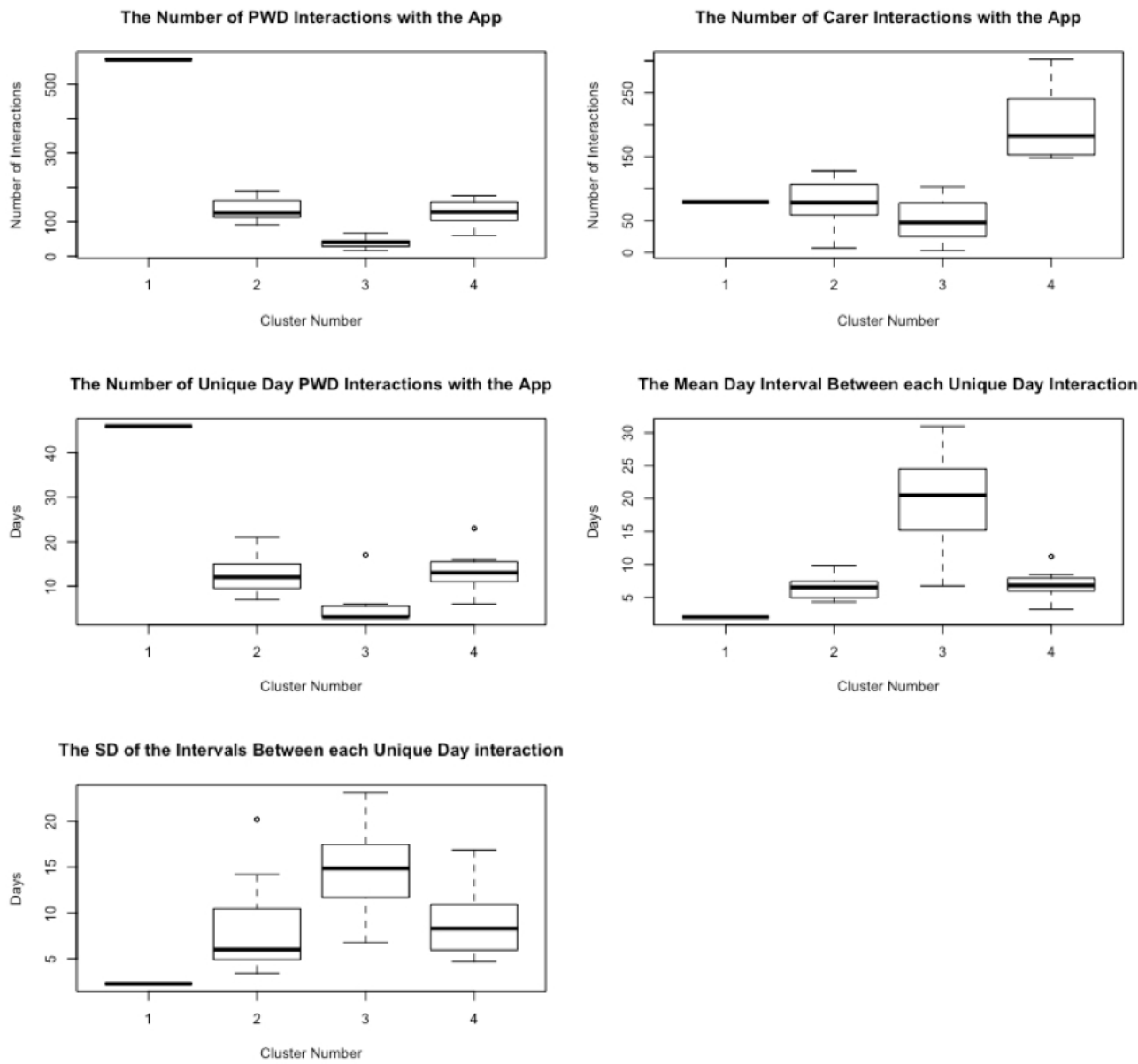

Figure 4. Each box-plot shows the distribution of each variable in each cluster. This shows the extent to which each individual feature discriminates between the clusters.

$164 \times 157 \mathrm{~mm}(150 \times 150 \mathrm{DPI})$ 